\title{
Alzheimer disease: Non- pharmacological and pharmacological management of cognition and neuropsychiatric symptoms
}

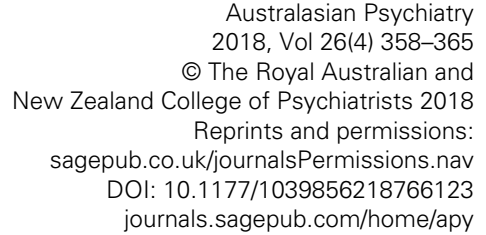

@SAGE

\footnotetext{
Samantha M Loi ${ }^{-1 D}$ Neuropsychiatrist, Department of Psychiatry, University of Melbourne and NorthWestern Mental Health, Parkville, VIC, Australia
}

Dhamidhu Eratne Neuropsychiatrist, Melbourne Neuropsychiatry Centre, University of Melbourne and NorthWestern Mental Health, Parkville, VIC, Australia

Wendy Kelso Neuropsychologist, Melbourne Neuropsychiatry Centre, University of Melbourne and NorthWestern Mental Health, Parkville, VIC, Australia

Dennis Velakoulis Neuropsychiatrist, Melbourne Neuropsychiatry Centre, University of Melbourne and NorthWestern Mental Health, Parkville, VIC, Australia

Jeffrey CL Looi iD Neuropsychiatrist, Melbourne Neuropsychiatry Centre, University of Melbourne, Parkville, VIC, and; Academic Unit of Psychiatry and Addiction Medicine, Australian National University Medical School, Canberra, ACT, Australia

\begin{abstract}
Objectives: This clinical update review focuses on the management of cognition and the neuropsychiatric features of Alzheimer's disease (AD) and highlights current issues regarding pharmacological and non-pharmacological treatment, putative therapeutics and recent relevant research findings in this area.

Conclusions: AD is a neurodegenerative progressive condition characterised by cognitive impairment and functional decline. Most people with $\mathrm{AD}$ will demonstrate neuropsychiatric features, better known as behavioural and psychological symptoms of dementia (BPSD). Early recognition and treatment of BPSD are essential, as these cause considerable distress and carer burden. While there are many disease-modifying therapies for the cognitive symptoms still in the research stage, only symptomatic treatments are currently available for these and the BPSD.
\end{abstract}

Keywords: alzheimer's disease, behavioural and psychological symptoms of dementia, psychiatry, neuropsychiatric symptoms

'Memories were waiting at the edges of things, beckoning to me.'

- Neil Gaiman, The Ocean at the End of the Lane. (or behavioural and psychological symptoms of dementia, BPSD). Family and carers, and the person with $\mathrm{AD}$ have essential roles in collaborating on the management of these symptoms.

The management of Alzheimer's disease (AD) is complex and requires a multidisciplinary approach, involving a range of clinicians, including a medical specialist (neurologist, psychiatrist, geriatrician), general practitioner (GP), nursing and allied health professionals (social worker, occupational therapist, psychologist). The major management issues to consider are listed in Table 1. This paper will focus on the management of $\mathrm{AD}$ and neuropsychiatric symptoms
Corresponding author:

Samantha M Loi, Melbourne Neuropsychiatry Unit, Royal Melbourne Hospital, Department of Psychiatry, University of Melbourne and NorthWestern Mental Health, John Cade Level 2, Grattan Street, Parkville, VIC 3050, Australia.

Email: Samantha.loi@unimelb.edu.au 


\section{Table 1. Major management issues to consider}

Cognitive symptoms - initially short-term memory impairment; then loss of visuospatial and language skills; late - loss of insight

Behavioural and psychological symptoms of dementia (BPSD) - depression, anxiety, psychosis, irritability, agitation, aggression Medical issues - weight loss, swallowing/choking problems, sleep disturbance, complications from late-life AD

Social issues - employment, finances, power of attorney/financial administrator, wills, driving, support for the family, psychoeducation

AD: Alzheimer's disease.

\section{Box 1. See case study from paper $1, R W^{1}$}

After the diagnosis of Alzheimer's disease (AD) was given, RW had a thorough physical examination and general investigations, such as a full blood count, renal, thyroid and liver function tests. She also had an electrocardiogram. Written information and psychoeducation about $\mathrm{AD}$ and donepezil was provided to her and her family. Donepezil was commenced at 5 mg mané for 4 weeks and this was increased to $10 \mathrm{mg}$ thereafter, with no significant adverse effects. The family also wanted to try Souvenaid, and they were able to purchase this from the local pharmacy.

\section{Challenges}

The major challenge is the absence of disease-modifying treatments for $\mathrm{AD}$. As Eratne et al. outlined in paper 1, the pathophysiology of $\mathrm{AD}$ remains unclear. Deposition of amyloid plaques (composed of amyloid beta, $A \beta$ ), neurofibrillary tangles (composed of tau), iron, vascular contribution, etc., may all be involved. The presence of amyloid plaques at least 15-20 years prior to initial clinical manifestations suggests that, when available, combinations of disease-modifying therapies may have to be commenced at the very early stages of the disease to target insidious pathophysiological processes.

\section{Pharmacological treatments for cognitive symptoms of AD}

$\mathrm{AD}$ is the most common type of dementia and currently the only available treatments target symptoms of $\mathrm{AD}$, such as slowing cognitive decline, and/or treat neuropsychiatric manifestations, while other treatments may be needed for other types of dementia. (see section on BPSD below). The cholinesterase inhibitors (donepezil, galantamine and rivstagimine) and the N-methylD-aspartate receptor antagonist, memantine, are licensed for treating $\mathrm{AD}$ and produce modest improvements in cognition and neuropsychiatric symptoms for some patients. The putative mechanism of action is through increasing cholinergic signalling and reducing excessive excitatory glutamatergic activity (cholinergic inhibitors and memantine, respectively). In New Zealand, memantine is not currently not subsidised, which may limit its use). In 2008, a transdermal patch for rivastigmine became available and in 2010, a slow-release version of donepezil became available $(23 \mathrm{mg})$. In some parts of Asia, an orally disintegrating formulation of donepezil is also available. In general, cholinesterase inhibitors are introduced once mild AD is diagnosed, while memantine is introduced as an adjunctive treatment as persons with AD develop moderate disease manifesting dysfunction in activities of daily living (ADLs). Unfortunately, both cholinesterase inhibitors and memantine have not been shown to be effective in mild cognitive impairment which may precede AD.

Side-effects are generally mild and tolerable, and include gastrointestinal side effects such as diarrhoea and nausea. Vivid dreams are an occasional complaint. Caution is advised in people who have obstructive respiratory (such as asthma or obstructive pulmonary disease) and cardiovascular conditions (an electrocardiogram is recommended prior to commencement of these medications). Substituting one cholinesterase inhibitor for an alternative may assist, or using the rivastigmine patch may ameliorate these side-effects (Box 1).

There are many nutraceuticals for which there is limited evidence of benefit, such as fish oil and gingko biloba. There is limited evidence on the benefits of Souvenaid, a dietary drink containing fatty acids, vitamins and other nutrients.

There have been over 200 other drugs which have reached phase 2 development between 1984 to now, but none have been approved for routine use. Passive vaccines containing monoclonal antibodies in prodromal $\mathrm{AD}$ have yielded promising results. Table 2 shows a selection of current trials (please refer to the recommended reading list in the online appendix for further information on this topic). 
Table 2. Selected medications currently being trialled - as of October 2017

\begin{tabular}{|c|c|c|c|c|}
\hline Target & Name & Therapy Type & Trial Status & Comments \\
\hline \multirow[t]{4}{*}{$A \beta$ clearance } & CAD106 & $\begin{array}{l}\text { Active } \\
\text { immunotherapy }\end{array}$ & Phase $2 / 3$ & $\begin{array}{l}\text { Administration to APP-transgenic mice } \\
\text { showed reduced brain } A \beta \text { accumulation }\end{array}$ \\
\hline & Aducanumab & $\begin{array}{l}\text { Passive } \\
\text { immunotherapy }\end{array}$ & Phase 3 (ENGAGE) & $\begin{array}{l}\text { Dose-dependent reduction in amyloid } \\
\text { PET and cognitive decline in phase } 1 \mathrm{~b} \\
\text { trial; dose and APOE4 status-dependent } \\
\text { ARIA (amyloid-related imaging } \\
\text { abnormalities) }\end{array}$ \\
\hline & Crenezumab & $\begin{array}{l}\text { Passive } \\
\text { immunotherapy }\end{array}$ & Phase 3 (CREAD2) & $\begin{array}{l}\text { Negative/minimal clinical outcomes in } \\
\text { phase } 2 \text { and } 3 \text { trials }\end{array}$ \\
\hline & Solanezumab & $\begin{array}{l}\text { Passive } \\
\text { immunotherapy }\end{array}$ & Phase 3 (A4) & $\begin{array}{l}\text { Possible reduced rate of cognitive } \\
\text { decline in mild disease; negative } \\
\text { clinical outcomes in two phase } 3 \text { trials; } \\
\text { low rate of ARIA }\end{array}$ \\
\hline \multirow[t]{3}{*}{ BACE inhibitor } & Lanabecestat & Small molecule & $\begin{array}{l}\text { Phase } 3 \text { (AMARANTH, } \\
\text { DAYBREAK-ALZ) }\end{array}$ & $\begin{array}{l}\text { Reportedly well tolerated, reduced CSF } \\
\text { A } \beta\end{array}$ \\
\hline & Elenbecestat & Small molecule & $\begin{array}{l}\text { Phase } 3 \text { (MISSION } \\
\text { AD1) }\end{array}$ & $\begin{array}{l}\text { Reportedly well tolerated, reduced CSF } \\
\text { A } \beta\end{array}$ \\
\hline & LY3202626 & Small molecule & $\begin{array}{l}\text { Phase } 2 \text { (NAVIGATE- } \\
\text { AD) }\end{array}$ & $\begin{array}{l}\text { Well tolerated, dose-related reduction } \\
\text { in CSF } A \beta\end{array}$ \\
\hline$\gamma$-secretase inhibitor & NIC5-15 & Small molecule & Phase 2 & $\begin{array}{l}\text { Pinitol, a naturally occurring cyclic } \\
\text { sugar alcohol } \\
\text { reportedly also Notch-sparing } \\
\gamma \text {-secretase inhibitor }\end{array}$ \\
\hline Tau stabilisation & TPI-287 & Small molecule & Phase 1 & \\
\hline $\begin{array}{l}\text { Tau aggregation } \\
\text { inhibitor }\end{array}$ & LMTM (TRx0237) & Small molecule & Phase 3 & Negative phase 3 trial \\
\hline P-Tau clearance & AADvac-1 & $\begin{array}{l}\text { Active } \\
\text { immunotherapy }\end{array}$ & Phase 2 & Overall, well tolerated \\
\hline \multirow[t]{3}{*}{ Others } & Azeliragon & & Phase 3 & $\begin{array}{l}\text { Effects across glial inflammatory and } \\
\text { amyloid-related processes; improved } \\
\text { cognitive performance and reduced } \\
\text { decreased brain } A \beta \text { load in transgenic } \\
\text { mice }\end{array}$ \\
\hline & Deferiprone & & Phase 2 (3D) & Iron-chelating agent \\
\hline & Xanamem & & Phase 2 (XanADu) & $\begin{array}{l}\text { Inhibitor of } 11 \beta \text {-hydroxysteroid } \\
\text { dehydrogenase, an enzyme in the } \\
\text { hypothalamic-pituitary-adrenal (HPA) } \\
\text { axis }\end{array}$ \\
\hline
\end{tabular}

A $\beta$ : amyloid beta; APP: amyloid precursor protein; APOE4: apolipoprotein E4; BACE: $\beta$-secretase; CSF: cerebrospinal fluid; PET: positron emission tomography.

\section{Behavioural and psychological symptoms of dementia (BPSD)}

The behavioural and psychological symptoms of dementia occur in most people who have $\mathrm{AD}$ and especially in those who are living in residential care (see Table 3). BPSDs are major precipitants of a person entering resi- dential care and can occur at any stage of dementia, though delusions, hallucinations, anxiety, irritability and disinhibition are reported with similar severity at all stages. A general medical assessment to ensure there are no concurrent medical (i.e. delirium), physical or environmental (Table 4) factors is important. The aetiology of BPSD is not well understood but is likely multifactorial. 
Table 3. Types of behavioural and psychological symptoms of dementia

Psychotic symptoms

Mood symptoms

Restless/agitated behaviours

Disinhibited behaviours
Delusions, hallucinations, misidentification

Depression, anxiety, apathy, euphoria

Aggression, agitation, wandering, vocally disruptive behaviours, nocturnal disruption

Socially inappropriate behaviour, uncontrolled eating, sexually inappropriate behaviour

Reproduced from Loi SM, Westphal A, Ames D, et al. Minimising psychotropic use for behavioural disturbance in residential aged care. Aust Fam Physician 2015; 44: 180-184 with permission from The Royal Australian College of General Practitioners. ${ }^{2}$

Table 4. Other external factors contributing to behavioural and psychological symptoms of dementia

\section{Physical factors}

Pain

Dehydration

Infection

Constipation

Medication changes

\section{Environmental factors}

Temperature sensitivity

Isolation, unmet needs

Change of routine and staff

Noise, overstimulation, boredom

Communication style/body language (carer)

Table 5. Valid scales for assessment of behavioural and psychological symptoms of dementia (BPSD)

\section{General BPSD}

Neuropsychiatric Inventory (NPI)

Behavioural pathology in AD (BEHAVE-AD)

Behavioural Symptoms Scale in Dementia (BSSD)

\section{Specific BPSD}

Cohen-Mansfield Agitation Inventory (CMAl)

Frontal System Behaviour Scale (FrSBe)

Brief Agitation Rating Scale (BARS)

Apathy Inventory (Al)

Rating scale for Aggressive Behaviour in the Elderly (RAGE)

Rating Anxiety in Dementia (RAID)

Algase Wandering Scale (AWS)

Cornell Scale for Depression in Dementia (CSDD)

\section{Assessment challenges for behavioural and psychological symptoms of dementia}

Comprehensive assessment is required, but this can be challenging as the person with $\mathrm{AD}$ may have difficulty communicating or co-operating. Table 5 shows a variety of scales available for assessing BPSD, which can be divided into general and specific measures and have a variety of advantages and disadvantages. Important assessment questions are displayed in Table 6.

As well as the validated scales, real-time assessment tools may also be useful in capturing this practical information. ${ }^{3}$

\section{Non-pharmacological management of behavioural and psychological symptoms of dementia}

The limited evidence-base and concern about safety in psychotropic medication have led to recommendations that non-pharmacological strategies are first-line in BPSD, though both are often utilised together. There is a substantial literature on various non-pharmacological strategies, limited by small sample sizes, lack of blinding and randomised design. Five recent review papers informed Table 7 and are listed in the recommended readings (high-level 1, consistent evidence; low-level 5, inconsistent evidence). There is little evidence for specific treatments of certain BPSDs, such as wandering and vocalisation. In general, the best evidence-based approaches are individualised and person-centred. It is important to note that such non-pharmacological strategies may be more resource intensive.

Carers play an important role in the management of BPSD and are often unaware of their own role in modifying BPSD. Table 8 outlines a variety of factors for carers and staff to consider when implementing a behavioural management plan. 


\section{Table 6. Assessment questions for behavioural and psychological symptoms of dementia}

What behaviours does the person with dementia usually present with?

What has changed/what are the behaviours now?

When and where does the BPSD occur?

How is the BPSD affecting the person with dementia, staff and others?

Has anything recently changed, such as new/changed medication, illness, environmental differences (change of staff, family member unable to visit, new resident)?

Any identifiable triggers to the BPSD, such as shower time or meal times?

Are there any strategies that seem to help?

What are the risks to the person with dementia?

What do the family/carers think about the new behaviours?

Adapted Loi SM, Westphal A, Ames D, et al. Minimising psychotropic use for behavioural disturbance in residential aged care. Aust Fam Physician 2015; 44: 180-184 with permission from The Royal Australian College of General Practitioners. ${ }^{2}$

BPSD: behavioural and psychological symptoms of dementia.

Table 7. Non-pharmacological strategies in behavioural and psychological symptoms of dementia

\begin{tabular}{|c|c|c|}
\hline Strategy & Type of BPSD & Rating \\
\hline Sounds (mountain stream, ocean waves) & Verbal aggression & Moderate-high \\
\hline Preferred music & $\begin{array}{l}\text { Verbal aggression during bath and meal } \\
\text { times }\end{array}$ & Moderate-high \\
\hline Preferred music & Apathy & Low-moderate \\
\hline $\begin{array}{l}\text { Staff training (consisting of meetings, psychoeducation, } \\
\text { behaviour management techniques) }\end{array}$ & Aggression & High \\
\hline $\begin{array}{l}\text { Carer training (consisting of psychoeducation, behaviour } \\
\text { management techniques, problem solving) }\end{array}$ & Aggression & High \\
\hline Individual recreational activities & Mood - positive effect observed & High \\
\hline $\begin{array}{l}\text { Stimulated family presence and use of personalised } \\
\text { audiotapes }\end{array}$ & Agitation & Moderate \\
\hline 'Bed baths' & Agitation, aggression & Moderate \\
\hline $\begin{array}{l}\text { Aromatherapy (lavender oil, lemon balm) - individual or } \\
\text { group setting }\end{array}$ & $\begin{array}{l}\text { Agitation, irritability, dysphoria - residents } \\
\text { seemed more engaged and less isolated }\end{array}$ & Moderate-high \\
\hline Cognitive stimulation & Neuropsychiatric symptoms & Moderate \\
\hline Reminiscence therapy & Agitation & Low \\
\hline Pet therapy & Apathy & Low-moderate \\
\hline Bright light therapy & Wandering & Low \\
\hline
\end{tabular}

Reproduced Loi SM, Westphal A, Ames D, et al. Minimising psychotropic use for behavioural disturbance in residential aged care. Aust Fam Physician 2015; 44: 180-184 with permission from The Royal Australian College of General Practitioners. ${ }^{2}$

BPSD: behavioural and psychological symptoms of dementia.

\section{Pharmacological management of BPSD}

Due to the risks of adverse effects and interactions with other medications, pharmacological strategies are second-line. In general, medications should be used to manage specific BPSD clinical syndromes. Antidepressants and antipsychotics may be beneficial in treating depressive and psychotic symptoms, respectively (but see Banerjee et al. ${ }^{5}$ ). General treatment principles for older adults are important: start at a low dose with gradual increases, regular reviews, and consideration of other comorbid medical conditions and medications. Discussion 


\section{Table 8. Factors to consider when managing behavioural and psychological symptoms of dementia}

(1) Brain functions that have been affected by dementia

To manage BPSD, the carer requires information from a specialist or GP about what functions of the brain are likely to be affected by dementia and therefore impact on communication, cognition and behaviour

(2) The individual

It is important to develop behavioural management plans based on the individual person. This includes his or her personality, age, past experiences, hobbies, likes and dislikes and the things that are important to him or her. The family and carer are best placed to contribute this knowledge.

(3) The behaviour of the carer

BPSD can be exacerbated when the person with dementia perceives that the carer is frustrated, angry or emotional. Whenever possible, carers should try to remain calm and in control when managing behavioural symptoms. The method of communication should be considered, including engagement, eye contact, tone, delivery and non-verbal cues.

(4) The environment

The environment should be modified to enable the person with dementia to use his or her skills. For example, to enhance social communication, conversations should occur in a quiet place, with minimal disruptions. The physical environment may need to be modified to reduce disorientation and overstimulation, leading to anxiety, agitation and/or wandering.

Adapted from Quality Dementia Care Series 5, Younger onset dementia: a practical guide, 2015 revision. Alzheimer's Australia. BPSD: behavioural and psychological symptoms of dementia; GP: general practitioner. ${ }^{4}$

Table 9. Examples of pharmacological management

\begin{tabular}{|c|c|c|c|}
\hline Indications & Medications & Examples & Side effects \\
\hline $\begin{array}{l}\text { Agitation } \\
\text { Aggression } \\
\text { Restlessness }\end{array}$ & $\begin{array}{l}\text { Antipsychotics } \\
\text { Benzodiazepines } \\
\text { Mood stabilisers }\end{array}$ & $\begin{array}{l}\text { Atypical (risperidone, } \\
\text { olanzapine, aripiprazole) } \\
\text { Diazepam, oxazepam } \\
\text { Valproate }\end{array}$ & $\begin{array}{l}\text { Metabolic syndrome, rigidity, } \\
\text { sedation, falls, balance problems, } \\
\text { increased risk of stroke and sudden } \\
\text { death, OTc prolongation } \\
\text { Sedation, falls, tolerance, } \\
\text { withdrawal, worsening cognition } \\
\text { Weight gain, sedation, blood } \\
\text { dyscrasias }\end{array}$ \\
\hline Depressive symptoms & $\begin{array}{l}\text { Selective serotonin reuptake } \\
\text { inhibitors (SSRIs) } \\
\text { Selective noradrenergic } \\
\text { reuptake inhibitors (SNRIs) } \\
\text { NASSAs, others }\end{array}$ & $\begin{array}{l}\text { Sertraline, citalopram, } \\
\text { escitalopram } \\
\text { Venlafaxine, desvenlafaxine, } \\
\text { duloxetine } \\
\text { Mirtazapine }\end{array}$ & $\begin{array}{l}\text { Agitation, sexual side effects, } \\
\text { hyponatraemia } \\
\text { See above } \\
\text { Sedation, increased appetite/weight } \\
\text { gain }\end{array}$ \\
\hline $\begin{array}{l}\text { Psychotic symptoms } \\
\text { Anxiety symptoms }\end{array}$ & $\begin{array}{l}\text { Antipsychotics } \\
\text { SSRls } \\
\text { SNRIs } \\
\text { NASSAs, others } \\
\text { Benzodiazepines }\end{array}$ & $\begin{array}{l}\text { See above } \\
\text { See above }\end{array}$ & $\begin{array}{l}\text { See above } \\
\text { See above }\end{array}$ \\
\hline
\end{tabular}

QTc: OT interval on an electrocardiogram; NASSAs: noradrenergic and specific serotonergic antidepressants.

with the patient, families and carers about the need for and potential side effects of medication, and how to monitor for side effects is essential (Box 2).

Risperidone is the only atypical antipsychotic subsidised and approved for use in Australia for BPSD and can improve psychosis, agitation and aggression. Table 9 lists examples of medications, their possible indications for specific symptoms and side-effects. BPSDs such as vocalisation, wandering, reverse sleep-wake cycle, and sexually inappropriate behaviours do not usually respond well to medications. Specialist clinicians such as psychiatrists may 


\section{Box 2. Case study continued...}

With the support of local services, the family were able to take turns looking after RW as she continued to deteriorate and required more support for personal activities of daily living, such as showering, toileting and dressing, and required supervision for concern of wandering. She started becoming verbally and physically aggressive towards her family and formal carers during shower times, possibly due to lack of recognition. She also became doubly incontinent. RW was then transferred to a residential care facility. Unfortunately, she continued to be aggressive and agitated, particularly during personal care. The facility staff contacted the local Aged Psychiatry team who recommended a delirium screen, including a urine test. The staff were also asked to complete a behaviour chart in order to ascertain when the behaviours occurred and in what context. It was elicited that a particular staff member was able to manage RW during shower times, possibly because she also spoke Maltese. Thus, the facility attempted to have this staff member work with RW as often as possible. Upon speaking to the family, the facility also managed to change the shower time to as late in the day as possible, as this was when RW was used to having a shower. A regular dose of risperidone of $0.25 \mathrm{mg}$ an hour prior to showering was also trialled.

feel pressured by aged care facility staff, general practitioners and families, to prescribe 'something' for BPSD. Often, by the time a person with dementia is being reviewed by a specialist, the BPSD has not responded to non-pharmacological measures. It is still important that the specialist perform a thorough assessment as described earlier. Both atypical (e.g. risperidone, quetiapine, olanzapine) and typical antipsychotics (e.g. haloperidol) and/or benzodiazepines (e.g. diazepam, oxazepam) have been prescribed individually, and in combination by specialists to manage BPSD. However, there remains limited evidence supporting the use of antipsychotics in dementia with significant adverse effects such as stroke, prolonged QTc interval and exacerbation of existing cognitive impairment. The Royal Australian and New Zealand College of Psychiatrists have published a Professional Practice Guideline and have made recommendations. ${ }^{6}$

Simple analgesia such as regular paracetamol has been reported to reduce BPSD in residents in nursing homes. ${ }^{7}$ Donepezil and memantine may also improve BPSD. ${ }^{8}$

\section{Supporting carers}

Caring for someone with dementia can be physically and emotionally demanding. Family members and carers need further education and support when undertaking the caring role. High levels of carer burden and 'burnout' lead to earlier residential placement for the person with dementia. Carers are at increased risk of anxiety, depression and physical ill health, due to the side effects of the caring role. It is important that GPs and/or the treating specialist engage with the carer and ensure their mental health, physical safety and wellbeing is being closely monitored. Family members and carers often report that they do not have the opportunity to openly discuss their concerns with the treating medical professional. It is vital that the doctor can talk to the carer, without the person with dementia in the consulting room. This ensures that the carer can confidentially disclose any personal safety concerns as a result of the BPSD and discuss their emotional and physical wellbeing.
There are a variety of excellent educational and counselling programs and referral services available to support carers. Information regarding behavioural support services, respite and residential care can be accessed through a variety of national agencies (see Table 10 for recommended readings).

\section{Discussion and conclusions}

Pharmacological treatment for the cognitive symptoms of $\mathrm{AD}$ is based upon use of cholinesterase inhibitors and the N-methyl-D-aspartate antagonist, memantine. The majority of neuropsychiatric manifestations of $\mathrm{AD}$, commonly grouped as BPSDs, are best addressed by personalised non-pharmacological psychological and behavioural approaches. In moderate-to-severe cases, especially where there is significant suffering for the patient and/or carer stress due to risk to others (e.g. aggression, psychosis), judicious pharmacological treatment may be considered. Families and carers play a vital role in supporting the person with dementia and require education, support and respite to assist them in their role.

\section{Disclosure}

The authors report no conflict of interest. The authors alone are responsible for the content and writing of the paper.

\section{Funding}

The authors received no financial support for the research, authorship, and/or publication of this article.

\section{ORCID iD \\ Samantha M Loi (D) https://orcid.org/0000-0002-4953-4500 \\ Jeffrey CL Looi https://orcid.org/0000-0003-3351-6911}

\section{References}

1. Eratne D, Loi SM, Farrand S, et al. Alzheimer's Disease Paper 1: Clinical Update on Epidemiology, Pathophysiology and Diagnosis. Australas Psychiatr 2018: in press.

2. Loi SM, Westphal A, Ames D, et al. Minimising psychotropic use for behavioural disturbance in residential aged care. Aust Fam Physician 2015; 44: 180-184. 
3. Loi SM, Wanasinghage S, Goh A, et al. A pilot study investigating the feasibility of Symptom Assessment Manager (SAM), a web-based real time tool for monitoring challenging behaviours. Int J of Geriatric Psychiatr 2018; 33: 576-582.

4. Hodges JR, McKinnon, Kelso W, et al. Dementia Australia Quality Dementia Care Series 5, Younger onset dementia: a practical guide, 2015 revision. Sydney: Alzheimer's Australia.

5. Banerjee S, Hellier J, Dewey M, et al. Sertraline or mirtazapine for depression in dementia (HTA-SADD): a randomised, multicentre, double-blind, placebo-controlled trial. Lancet 2011; 378: 403-411.
6. The Royal Australian and New Zealand College of Psychiatrists. Professional Practice Guideline 10: antipsychotic medications as a treatment of behavioural and psychological symptoms of dementia. https://www.ranzcp.org/Files/Resources/ College_Statements/Practice_Guidelines/pg10-pdf.aspx (2016, accessed 12 December 2017).

7. Husebo B, Ballard C, Sandvik R, et al. Efficacy of treating pain to reduce behavioural disturbances in residents of nursing homes with dementia: cluster randomised clinical trials. BMJ 2011; 343: d4065.

8. Franchi B. Pharmacological management of behavioural and psychological symptoms of dementia. J Pharmacy Pract and Res 2016; 46: 277-285. 